\title{
Editorials
}

\section{AVIAN INFLUENZA A(H5N1) - CURRENT SITUATION}

\author{
A Melidou (amelidou@med.auth.gr) ${ }^{1}$ \\ 1. National Influenza Centre for northern Greece, B Dept of Microbiology, Medical School, Aristotle University of Thessaloniki, \\ Thessaloniki, Greece
}

The $\mathrm{A}(\mathrm{H} 5 \mathrm{~N} 1)$ influenza virus has re-emerged in 2003 in Asia, Africa, the Pacific Region as well as Europe and since then has become endemic in some countries. The virus is usually highly pathogenic and is associated with high morbidity and overall mortality rates that reach $61 \%$. The cumulative number of confirmed human cases from 2003 to 2009 is 423 cases, with 258 deaths [1]. During the current year, sporadic human infections have occurred only in Egypt, China and Vietnam. In Egypt, no deaths have been reported from a total of 17 confirmed human cases in 2009 , which could be an indication of altered pathogenicity of the circulating strains [2]. The article of JP Dudley published in this issue of Eurosurveillance [3] examines the age- and sex-specific rates of infection and mortality for human cases of avian influenza $A(H 5 N 1)$ virus in Egypt, concluding that they differ markedly from those recorded in other countries. Accelerated evolution of H5N1 was previously reported in the area, and was possibly linked to the vaccine program, as evolved circulating strains can escape from recent vaccines [4].

Ongoing research is focused on the development of appropriate vaccines against $A(H 5 N 1)$ circulating strains for use in humans. Clade $2.2 \mathrm{~A}(\mathrm{H} 5 \mathrm{~N} 1)$ influenza viruses that have been associated with human infections in Egypt since September 2008 are the ones with the most geographically disperse distribution and have caused outbreaks in poultry in over 60 countries in Asia, Africa and Europe. Human infections in China and Vietnam have been associated with clade 2.3 viruses. A number of reassortants have completed and others are awaiting regulatory approval to be used in vaccine production in affected areas. As antigenic heterogeneity occurs, vaccine candidates are being re-evaluated [4].

While at the moment attention is focused on the recent emergence of a new influenza $A(H 1 N 1)$ virus, other influenza viruses, including the avian influenza $A(H 5 N 1)$ strains, are still a cause for concern. With studies such as the one presenting data from Egypt the importance of constant monitoring of the geographic spread and epidemiology of circulating strains, and the determination of their genetic and antigenic characteristics is highlighted.
2. United States Naval Medical Research Unit No. 3 (NAMRU-3). Influenza Activities Report. February - March 2009. Available from: http://www.geis.fhp.osd.mil GEIS/SurveillanceActivities/Influenza/Reports/NAMRU3_March_2009.pdf

3. Dudley JP. Age-specific infection and death rates for human A(H5N1) avian influenza in Egypt. Euro Surveill. 2009;14(18):pij=19198. Available from: http:// www.eurosurveillance.org/ViewArticle. aspx?ArticleId $=19198$

4. World Health Organization. Antigenic and genetic characteristics of H5N1 viruses and candidate vaccine viruses developed for potential use in human vaccines, 2009 February. Available from: http://www who.int/csr/disease/ avian_influenza/guidelines/200902_H5VaccineVirusUpdate.pdf

This article was published on 7 May 2009.

Citation style for this article: Melidou A. Avian influenza A(H5N1) - current situation. Euro Surveill. 2009;14(18):pij=19199. Available online: http://www.eurosurveillance.org/ ViewArticle.aspx?ArticleId $=19199$

\section{References}

1. World Health Organization. Cumulative number of confirmed human cases of avian influenza A(H5N1) reported to WHO. [Accessed 6 May 2009] Available from: http://www.who.int/csr/disease/avian_influenza/country/cases_ table_2009_05_06/en/index.html 